\title{
PAULO FREIRE E O INÉDITO VIÁVEL: ESPERANÇA, UTOPIA E TRANSFORMAÇÃO NA SAÚDE
}

\author{
PAULO FREIRE AND UNTESTED FEASIBILITY: \\ HOPE, UTOPIA AND TRANSFORMATION IN HEALTH
}

\author{
César Augusto Paro ${ }^{1}$ (D) [0000-0002-8447-9586], Miriam Ventura ${ }^{1}$ (D) [0000-0001-8520-8844], Neide Emy \\ Kurokawa e Silva ${ }^{1}$ iD [0000-0002-1314-8851] \\ ${ }^{1}$ Universidade Federal do Rio de Janeiro, Instituto de Estudos em Saúde Coletiva, Rio de Janeiro, RJ, \\ Brasil. <cesaraugustoparo@iesc.ufrj.br>
}

Resumo Trata-se de ensaio sobre o constructo 'inédito viável', de Paulo Freire, com objetivo de explorar suas potencialidades na saúde coletiva. Foram analisadas 38 obras do autor, das quais nove abordavam o inédito viável, permitindo reconhecer significados subjacentes ao constructo. Foram explorados três eixos para a compreensão: condições e contextos de emergência dos inéditos viáveis; exemplos; e sentidos de inéditos viáveis. A emergência dos inéditos viáveis resulta de complexo processo pedagógico, que vai do estranhamento da realidade à percepção crítica dos sujeitos envolvidos, a qual propicia a construção dos inéditos viáveis, como etapa que antecede a ação. Embora algumas obras analisadas citem exemplos de inéditos viáveis, estes não foram elucidativos na apreensão de possíveis significados do inédito viável. Com base nas ideias da obra freireana de práxis, projeto, futuridade, sonho, utopia e esperança, a compreensão do inédito viável ancorou-se no sentido de projeto coletivo. Propõe-se uma pedagogia aplicada à saúde coletiva que incorpore o 'inédito viável' como possibilidade de transcender o adestramento técnico, baseado, exclusivamente, em conteúdos informativos, investindo, também, nas capacidades de indignação e denúncia e na construção de projetos coletivos.

Palavras-chave inédito viável; educação popular; transformação social; esperança; utopia.
Abstract This essay is about Paulo Freire's "untested feasibility" construct, and it aims to explore its potentialities in collective health. A total of 38 works by the author were analyzed, nine of which discuss untested feasibility, which enables the recognition of the construct's underlying meanings. Three core ideas were explored for this understanding: the conditions and contexts of emergency of the untested feasibilities; examples; and the meanings of the untested feasibilities. The emergence of untested feasibilities results from a complex pedagogical process, which goes from the defamiliarization regarding reality to the critical perception of the subjects involved, which contributes to the development of untested feasibilities, as a step that precedes action. Even though some of the analyzed works mention examples of untested feasibilities, those were not clarifying regarding the understanding of the possible meanings of untested feasibility. Based on the ideas contained in Freire's works regarding praxis, project, futurity, dream, utopia and hope, the comprehension of untested feasibility was based on the sense of collective project. We propose a pedagogy applied to collective health that incorporates "untested feasibility" as a possibility of transcending the technical training, which is based exclusively on informational contents, also investing in the capacities of indignation and denunciation and in the development of collective projects.

Keywords untested feasibility; popular education; social transformation; hope; utopia. 


\section{Introdução}

Com maior ou menor coerência e rigor na incorporação das bases de sua pedagogia, a proposta de Paulo Freire alcança, de modo expressivo, a produção acadêmica e as práticas de saúde no Brasil, para além da educação.

É de se entender que parte das diferentes aproximações ao seu legado pedagógico pela saúde deve-se ao fato de que esse setor é historicamente marcado pela centralidade na transmissão de informações e mudança de comportamentos, gerando tensionamentos entre tal centralidade e a dialogia freireana. Basta lembrar que, a despeito das possíveis controvérsias quanto à sua definição (Mantovani, 2018), a chamada polícia médica radicaliza a representação de uma proposta verticalizada - e mesmo repressiva - tanto nas práticas de educação em saúde quanto na saúde em geral, sendo reproduzida até os dias de hoje.

Contrapondo-se a essa ideia e partindo da crítica à mercantilização e rotinização do trabalho dos serviços oficiais, profissionais que buscavam assimilar o ideário freireano ao contexto da saúde iniciaram um movimento na década de 1970. Tal iniciativa propunha a integração do trabalho desses profissionais às experiências informais da igreja católica nas periferias das grandes cidades e zonas rurais, assim como de multiplicação de serviços de atenção primária à saúde, o que possibilitou que a educação popular se tornasse um instrumento de reorientação das práticas de saúde nestas experiências (Vasconcelos, 2001).

Os pilares democráticos e participativos da Constituição Federal brasileira deram a sustentação para a formalização da Política Nacional de Educação Popular em Saúde (Brasil, 2012). A educação popular ${ }^{1}$ traz no seu âmago um caráter propositivo e transformador, preocupa-se com a formação de sujeitos críticos, problematizadores, protagônicos, esperançosos, tolerantes e autônomos, por meio de processos educativos dialógicos, libertários, solidários e transformadores.

Entretanto, a incorporação e a disseminação dos seus preceitos representam um grande desafio diante do contexto ainda hegemônico do cotidiano da saúde, que oscila entre o autoritarismo e o paternalismo. Este contexto nos convoca à reflexão crítica destas práticas, para um agir com vistas à transformação dos modos de se produzir saúde.

Paulo Freire deu traços próprios a conceitos como diálogo, liberdade e emancipação, os quais têm sido explorados com frequência na literatura acadêmica. Também construiu uma terminologia própria (Simões, 2013), prenhe de sentidos e coerentes com suas diferentes fontes - de Karl Jaspers a Karl Marx. Termos como dialogicidade, sloganização, ad-mirar, dentre tantos, fazem parte de seu vocabulário, inclusive constando em glossários próprios (Gadotti, 1996; Streck, Redin e Zitkoski, 2017). Para além do jargão acadêmico, expressões 
como 'roda de conversa' recebem diferentes gradientes de apropriação. Vão desde proposições sintonizadas com os horizontes vislumbrados pelo autor até aquelas que apenas se travestem de relações dialógicas e horizontalizadas de poder; estas, na prática, simplesmente reproduzem interações cujos saberes são hierarquizados.

Em meio à riqueza dos vocábulos freireanos, nota-se que um deles - o inédito viável - foi uma categoria, segundo Ana Maria Araújo Freire ${ }^{2}$ (2014a, p. 277), "pouco comentada e arrisco dizer pouco estudada". Deduz-se a importância do conceito partindo da leitura de que todo o processo pedagógico desenvolvido por Paulo Freire transcendia o caráter instrumental de saber ler e escrever ou de racionalizar o trabalho da lavoura. Tal transcendência referiase à transformação das relações de opressão, baseada na ação dos oprimidos. E essa ação que denuncia o status quo e, ao mesmo tempo, concretiza transformações, o ato-limite - que será retomado adiante -, é justamente possível a partir dos inéditos viáveis.

Tanto quanto no trabalho de alfabetização quanto com os camponeses, deduz-se igualmente a importância de explorar o conceito de inédito viável no âmbito da saúde, campo marcado pela reprodução de relações de desigualdades, muitas vezes naturalizadas ou vistas como insuperáveis. Dentre essas inúmeras situações, pode-se citar a hegemonia dos referenciais da biomedicina como a balizadora inquestionável nas práticas em saúde. Do mesmo modo, tem-se o poder do profissional médico e o seu conhecimento técnico (a despeito dos conhecimentos dos demais profissionais da saúde e da sabedoria popular), até a reprodução de processos de trabalho, que impõem sofrimento tanto à população quanto aos profissionais de saúde.

Este artigo tem como objetivo aprofundar o conhecimento sobre o constructo inédito viável e, assim, apreender e problematizar seus sentidos, bem como explorar suas potencialidades no contexto da saúde.

\section{Andanças e (re)criações com Freire: percurso metodológico}

Trata-se de um estudo de caráter qualitativo ${ }^{3}$, em que se assume a atitude epistemológica freireana de que "estudar não é um ato de consumir ideias, mas de criá-las e recriá-las" (Freire, 2016b, p. 14). Desenvolve-se, portanto, um ensaio que se caminha com Freire para a compreensão do inédito viável como conceito-chave para a produção de conhecimentos e fomento de transformações, especialmente nas práticas de saúde.

Os termos cunhados por Freire são profundamente coerentes com suas referências teóricas, éticas e políticas, sem, contudo, serem por elas aprisionados. São conceitos que estão lá, como um ponto de referência, à mercê da 
dinâmica dos diferentes contextos em que são lidos. Ou seja, não há preocupação em dizer o que são, mas muito mais o que podem vir a ser, por meio da ação. É com esse espírito que se pretende empreender um processo de descodificação que permita reconhecer significados subjacentes ao inédito viável.

Inicialmente, procedeu-se a um levantamento e à leitura dos livros publicados pelo autor, individualmente ou com coautores, em vida ou post mortem, escritos originalmente ou posteriormente publicados em português. Esse levantamento foi guiado pelas publicações listadas nas bibliografias sistematizadas nas obras Dicionário Paulo Freire (Freire, 2017a) e Pedagogia dos Sonhos Possiveis (Freire, 2014d), incluindo prefácios, posfácios e capítulos de outros autores em seus livros, totalizando um corpus de 38 livros analisados ${ }^{4}$. Também foram incluídas obras referenciadas nestes livros que se relacionavam com o inédito viável para subsidiar a discussão dos resultados.

Das 38 obras analisadas, as referências ao inédito viável foram identificadas em nove delas, publicadas entre 1968 e 2009, por cinco autores. Paulo Freire não chega a desenvolver um conceito claro sobre inédito viável em nenhuma dessas obras. No verbete desenvolvido por Ana Freire (2014a), sugere-se a abrangência do termo e, ao mesmo tempo, uma certa fluidez:

O 'inédito-viável' é na realidade, pois, uma coisa que era inédita, ainda não claramente conhecida e vivida, mas quando se torna um 'percebido destacado' pelos que pensam utopicamente, o problema não é mais um sonho, ele pode se tornar realidade (Freire, 2014a, p. 225).

Esta 'coisa' denominada como inédito viável é fruto de um complexo processo pedagógico, como se depreendeu das leituras selecionadas. Se Paulo Freire não se preocupou em dar ares de conceito ao termo, as condições de emergência dos inéditos viáveis são destacadas em sua obra.

Desse modo, procedeu-se a um levantamento e compreensão dessas condições e contextos que favorecem a construção de inéditos viáveis, bem como de exemplos que pudessem contribuir na sua elucidação.

Com tal intuito, foram identificadas todas as vezes em que o termo inédito viável $^{5}$ foi empregado pelos autores, sendo que estes trechos foram selecionados e organizados em três eixos: condições e contextos de emergência dos inéditos viáveis; exemplos de inéditos viáveis; e sentidos do inédito viável (Quadro 1).

A análise do material inspirou-se na análise temática, como modalidade da análise de conteúdo (Bardin, 2016). Tomou-se como unidade de análise os elementos identificados com cada um dos eixos selecionados, apreendendose núcleos de sentidos, construídos a partir do diálogo com outros conceitos da obra de Freire. Por fim, procedeu-se a uma reflexão sobre a noção, capaz de dar pistas para a área da saúde, especialmente no tocante às dimensões pedagógicas presentes nas suas práticas. 
Quadro 1.

Caracterização das obras com referência ao termo inédito viável

\begin{tabular}{|c|c|c|c|}
\hline Obra (ano) & Parte da obra (autoria) & Tipo de referência & Temas \\
\hline \multirow[t]{2}{*}{$\begin{array}{l}\text { Pedagogia do } \\
\text { Oprimido (1968) }\end{array}$} & $\begin{array}{l}\text { As relações homens-mundo, } \\
\text { os temas geradores e o } \\
\text { conteúdo programático } \\
\text { desta educação (PF) }\end{array}$ & Condições & $\begin{array}{l}\text { Situação-limite } \\
\text { Ato-limite } \\
\text { Percepção crítica } \\
\text { Libertação dos oprimidos }\end{array}$ \\
\hline & $\begin{array}{l}\text { A significação } \\
\text { conscientizadora da } \\
\text { investigação dos temas } \\
\text { geradores. Os vários } \\
\text { momentos da investigação } \\
\text { (PF) }\end{array}$ & Condiç̧̃es & $\begin{array}{l}\text { Consciência máxima possível } \\
\text { Soluções praticáveis despercebidas } \\
\text { Percepção crítica } \\
\text { Processo educativo }\end{array}$ \\
\hline \multirow{4}{*}{$\begin{array}{l}\text { Ação cultural para } \\
\text { a liberdade e outros } \\
\text { escritos (1975) }\end{array}$} & $\begin{array}{l}\text { Ação cultural e reforma } \\
\text { agrária (PF) }\end{array}$ & Condiç̧̃es & $\begin{array}{l}\text { Percepção crítica } \\
\text { Situação-limite }\end{array}$ \\
\hline & $\begin{array}{l}\text { O papel educativo das Igrejas } \\
\text { na América Latina (PF) }\end{array}$ & Exemplos & $\begin{array}{l}\text { Libertação dos oprimidos na sociedade de } \\
\text { classe }\end{array}$ \\
\hline & \multirow{2}{*}{$\begin{array}{l}\text { Conscientização e libertação: } \\
\text { uma conversa com Paulo } \\
\text { Freire (PF) }\end{array}$} & Condições & $\begin{array}{l}\text { Práxis } \\
\text { Situação dialética }\end{array}$ \\
\hline & & Sentidos & Futuridade a ser construída \\
\hline \multirow[t]{6}{*}{$\begin{array}{l}\text { Paulo Freire ao vivo } \\
\text { (1983) }\end{array}$} & \multirow[t]{2}{*}{$\begin{array}{l}\text { O aspecto metodológico } \\
\text { (WS) }\end{array}$} & Condiç̧̃es & $\begin{array}{l}\text { Passagem da consciência mágica para a crítica } \\
\text { Homem como construtor do mundo }\end{array}$ \\
\hline & & Sentidos & $\begin{array}{l}\text { Projeto a ser realizado } \\
\text { Utopia e não utopismo }\end{array}$ \\
\hline & \multirow[t]{3}{*}{$\begin{array}{l}\text { O embasamento filosófico } \\
\text { (AV) }\end{array}$} & Condições & $\begin{array}{l}\text { Práxis } \\
\text { Ação-reflexão }\end{array}$ \\
\hline & & Exemplos & Rapaz possível para ter um relacionamento \\
\hline & & Sentidos & $\begin{array}{l}\text { Criação de algo concreto, novo e possível para } \\
\text { as condições atuais e locais }\end{array}$ \\
\hline & $\begin{array}{l}3^{\circ} \text { Conferência - 07/11/80 } \\
\text { (PF) }\end{array}$ & Exemplos & Democracia \\
\hline \multirow{4}{*}{$\begin{array}{l}\text { Pedagogia da } \\
\text { esperança: um } \\
\text { reencontro com } \\
\text { a pedagogia do } \\
\text { oprimido (1992) }\end{array}$} & Prefácio (LB) & Sentidos & Inédito \\
\hline & \multirow[t]{2}{*}{$\begin{array}{l}\text { Seções 'Primeiras palavras' } \\
\text { e'Pedagogia da esperança' } \\
\text { (PF) }\end{array}$} & Condições & $\begin{array}{l}\text { Postura esperançosa } \\
\text { Luta pela superação dos obstáculos } \\
\text { Leitura do mundo possibilita a decifração crítica } \\
\text { da situação-limite } \\
\text { Inédito viável demanda dos sujeitos a luta } \\
\text { por ele } \\
\text { Ação articulada dos sujeitos históricos } \\
\text { Metáfora }\end{array}$ \\
\hline & & Exemplos & $\begin{array}{l}\text { Imigrantes, imersos na situação-limite de uma } \\
\text { anestesia história, não podiam divisar o inédito- } \\
\text { viável } \\
\text { Coisa inédita, ainda não conhecida e vivida, } \\
\text { mas sonhada }\end{array}$ \\
\hline & Notas explicativas (AMAF) & Condições & $\begin{array}{l}\text { Tornar-se um percebido destacado } \\
\text { Síntese de todos os elementos presentes em } \\
\text { Pedagogia do Oprimido } \\
\text { Percebido-destacado deve passar a ser um } \\
\text { tema-problema que precisa ser enfrentado } \\
\text { (discutido e superado) }\end{array}$ \\
\hline
\end{tabular}


Continuação do Quadro 1.

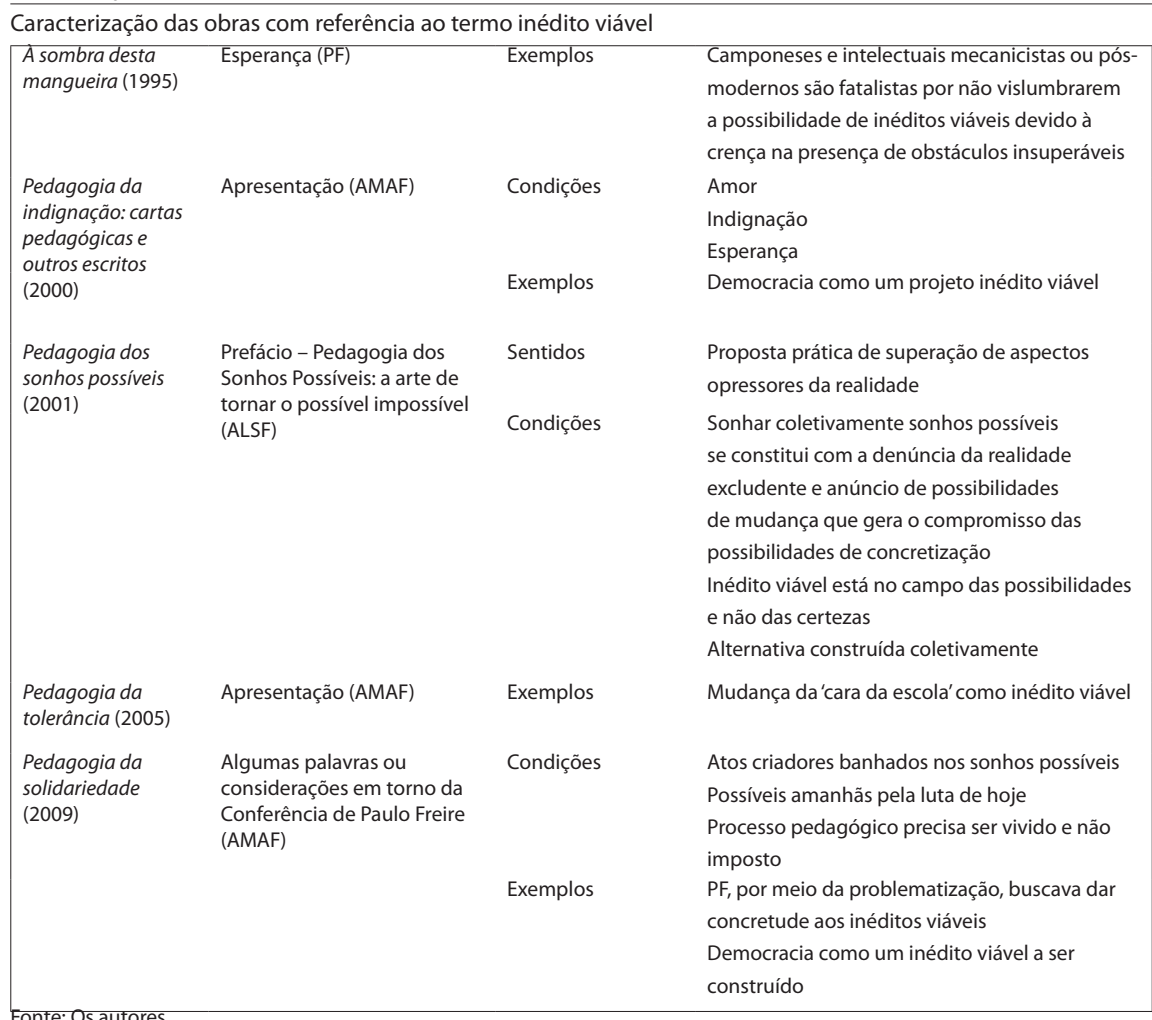

Nota: os anos referem-se ao da publicação da obra original.

Legenda: ALSF - Ana Lúcia Souza de Freitas, AMAF - Ana Maria Araújo Freire, AV - Aldo Vannucchi, LB - Leonardo Boff, PF - Paulo

Freire e WS - Waldemir Santos.

\section{Condições e contextos de emergência dos inéditos viáveis}

\section{Percepção crítica da realidade e superação das situações-limite}

A primeira obra de Freire em que emerge o termo inédito viável é Pedagogia do Oprimido. Esta é criada mediante o diálogo entre as categorias 'consciência máxima possível', do sociólogo e filósofo francês Lucien Goldmann (1969); 'soluções praticáveis despercebidas', do sociólogo francês André Nicolaï (1960) e 'situações-limite' e 'atos-limite', do filósofo brasileiro isebiano Álvaro Vieira Pinto (1960).

Em Paulo Freire, a terminologia em torno da palavra 'consciência' é vasta, valendo destacar aquelas mais afetas à ideia de inédito viável.

Primeiramente, é importante demarcar que a noção de consciência contrapõe-se à interpretação solipsista do termo, tomada usualmente como um ato relativo à psique dos indivíduos. Freire ressalta o seu caráter histórico, ou seja, como inserção crítica na história, de seres que, ao se assumirem como sujeitos, fazem e refazem o mundo (Freire, 2016b). 
Também há uma diferenciação entre consciência ingênua e consciência crítica: o primeiro termo corresponderia à apreensão ingênua da realidade, em que o sujeito, embora perceba os fenômenos, não sabe tomar um distanciamento deles, a fim de julgá-los; o segundo corresponderia ao movimento de tornar mais metodicamente rigorosa a curiosidade e o estranhamento da situação (Freire, 2018). Nas palavras do autor,

(...) a conscientização é o teste de realidade. Quanto mais nos conscientizamos, mais 'desvelamos' a realidade, e mais aprofundamos a essência fenomênica do objeto diante do qual nos encontramos, com o intuito de analisá-lo. Por essa razão, a conscientização não consiste num 'estar diante da realidade' assumindo uma posição falsamente intelectual. Ela não pode existir fora da práxis, ou seja, fora do ato 'ação-reflexão'. Esta unidade dialética constitui, de maneira permanente, o modo de ser, ou de transformar o mundo, e que é próprio dos homens (Freire, 2016b, p. 56-57).

Freire (2016d) postula que a organização do conteúdo programático da prática educativa dialógica deve ser feita fundamentada na situação presente, existencial e concreta, refletindo o conjunto de aspirações do povo. Nesse sentido, o autor propõe a investigação do seu universo temático e do conjunto de temas geradores, ou seja, temas que têm sentido e fazem parte do vocabulário popular, e pelos quais é possível desenvolver uma leitura crítica da realidade.

Tais temas geradores normalmente encontram-se envolvidos e envolvendo situações-limite - barreiras e obstáculos que precisam ser vencidos nas vidas pessoais e sociais de mulheres e homens (Freire, 2014a) - que se apresentam ao povo como se fossem determinantes históricos, para os quais só há a alternativa da adaptação.

A construção do inédito viável envolve o processo de codificação e descodificação ${ }^{7}$ da realidade, ou seja, codifica-se uma situação existencial concreta para, a partir daí, investir no processo de descodificação, que permitirá a análise crítica desta situação codificada. Isto implica um movimento do abstrato até o concreto, numa ida das partes ao todo e numa volta deste às partes, num reconhecimento do sujeito no objeto (a situação existencial concreta) e do objeto como situação em que está o sujeito (Freire, 2016d).

Ana Freire (2014a) vincula esta percepção à noção do percebido-destacado, que trata daquilo que é percebido e destacado na vida cotidiana dos sujeitos, como algo que não pode e nem deve permanecer como está, mas, pelo contrário, precisa ser enfrentado, ou seja, ser discutido e superado. Este percebido-destacado emerge do distanciamento das situações-limite, as quais, ao serem destacadas da realidade, podem ser objetivadas e compreendidas em sua profundidade, permitindo serem tomadas como temas-problema. Quando os sujeitos percebem claramente os desafios das situações-limite que passam 
a ser percebidos-destacados, sentem-se mobilizados a agir e a descobrirem o inédito-viável.

A superação das situações-limite ocorre por meio de atos-limite, que são compreendidos como respostas necessárias que se dirigem à superação e à negação do dado com uma postura decidida frente ao mundo (Freire, 2014a). Na percepção crítica da situação-limite, rumo ao ato-limite, estaria "implícito o inédito viável como algo definido, a cuja concretização se dirigirá sua ação" (Freire, 2016d, p. 130).

A consciência real, ou seja, aquela nas quais os homens se encontram limitados nas suas possibilidades de perceberem além das situações-limite, permitiria vislumbrar apenas 'soluções praticáveis percebidas', ao passo que a consciência possível ensejaria as 'soluções praticáveis despercebidas', ou seja, os inéditos viáveis, concretizáveis na ação editanda, cuja viabilidade antes não era percebida pelos sujeitos (Freire, 2016d).

Portanto, tem-se aqui a importância do processo de conscientização crítica para a emersão dos inéditos viáveis. Com base nesse processo, torna-se possível a criação de novas percepções da realidade, as quais permitem a identificação de ações possíveis, que antes não eram vislumbradas como soluções. Por isso, o autor aponta que a consciência real culmina em apenas soluções praticáveis percebidas, ao passo que a consciência possível permitiria alcançar soluções praticáveis despercebidas (Freire, 2016d).

\section{Perspectiva dialética e práxis}

Apontados os principais momentos e conceitos que constituiriam e justificariam o processo metodológico para a construção de inéditos viáveis, cabe trazer outro aspecto central que embasa essa construção e diz respeito à perspectiva dialética presente em toda a obra de Freire.

Considerando que a produção do autor é permeada e comprometida inteiramente com a ação, ressalta-se o caráter práxico de sua produção intelectual, ou seja, da coerência e articulação entre o que se pensa, o que se faz e o que se pensa acerca do que se faz. Os inéditos viáveis inserem-se nesse contexto práxico, de um processo dialético de conscientização que impulsiona a ação.

Em Ação cultural para a liberdade e outros escritos, Freire (2015) destaca o lugar da práxis na construção do inédito viável:

A concretização do 'inédito viável', que demanda a superação da situação obstaculizante - condição concreta em que estamos independentemente de nossa consciência - só se verifica, porém, através da práxis. Isso significa, enfatizemos, que os seres humanos não sobrepassam a situação concreta, a condição na qual estão, por meio de sua consciência apenas ou de suas intenções, por boas que sejam 
(...) Mas, por outro lado, a práxis não é a ação cega, desprovida de intenção ou de finalidade. É ação e reflexão (Freire, 2015, p. 221-222).

Tal qual a dialeticidade entre conhecimento da realidade-transformação da realidade, Freire demarca a rejeição a dicotomizações dualistas em favor de uma perspectiva dialética: sujeito-objeto, teoria-prática (2015), ação-reflexão, subjetividade-objetividade, condicionamentos-liberdade, permanência-mudança, possibilidades de mudar-dificuldades em mudar (2016d), denúncia-anúncio, leitura do mundo-leitura da palavra (2014d), positividades na cultura-negatividades na cultura, produção econômica-produção cultural e consciênciamundo (2014b).

Freire (2016b) também coloca em relevo a tônica na dialética e na práxis, ao discorrer sobre os atos de denunciar a estrutura desumanizante e anunciar uma estrutura humanizante:

Não posso denunciar a estrutura desumanizante se não a perscruto para conhecêla. Não posso anunciar se não conheço. No entanto, entre o momento do anúncio e a realização dele, há algo que precisa ser posto em evidência: o anúncio não é o anúncio de um projeto, mas, sim, de um anteprojeto, pois é na práxis histórica que o anteprojeto se faz projeto. É ao agir que posso transformar meu anteprojeto em projeto; em minha biblioteca tenho um anteprojeto que se torna projeto mediante a práxis, e não por meio do blá-blá-blá (Freire, 2016b, p. 58-59).

Zitkoski (2017, p. 116) destaca essa concepção dialética de Freire por meio da compreensão de história, e da importância da subjetividade humana na construção do mundo socioculturalmente estruturado: "um momento histórico posterior é algo novo, que jamais poderá ser predeterminado ou domesticado pelos momentos que antecedem, pois o futuro da história é algo a ser construído por nossa inserção no mundo".

\section{Esperança, utopia e sonho}

Além do caráter praxiológico e da perspectiva dialética em geral, que imprime a construção dos inéditos viáveis, destaca-se a consubstancialidade entre as dimensões ontológica e política, que movem a proposta freireana.

Colocando em evidência as relações excludentes e de injustiça, a leitura da realidade pode suscitar uma miríade de sentimentos envolvendo espanto, rebeldia, inconformismo, raiva, mas também coragem, ousadia e esperança. Nesse momento, faz-se presente o imbricamento entre as dimensões ontológica e política da pedagogia freireana, na medida em que a indignação e a esperança só se justificam quando são mobilizadoras de mudanças: 
A educação crítica é a 'futuridade' revolucionária. Sendo profética-enquanto tal, portadora de esperança -, corresponde à natureza histórica do homem. Ela afirma que os homens são seres capazes de se superar, que vão adiante e olham o futuro; seres para os quais a imobilidade representa um risco fatal, para os quais olhar o passado deve ser apenas um modo de compreender com maior clareza quem eles são e o que são para poder construir o futuro com mais sabedoria (Freire, 2016b, p. 134).

Paulo Freire (2014b) dedica uma obra especificamente para tratar da esperança-Pedagogia da Esperança -, na qual deixa claro que ela é uma necessidade ontológica e que a desesperança, ao contrário, fomenta o fatalismo e o imobilismo, que podem ser muito úteis aos grupos de dominação.

Tal fatalismo é retomado em À sombra desta mangueira, denunciando a postura de dependência entre camponeses, em face das situações-limite, que exigiriam "a superação desta percepção fatalista por outra, crítica, capaz de divisar mais além destas situações, o que chamamos de 'inédito viável'" (Freire, 2015, p. 50). Mesmo dentre alguns intelectuais mecanicistas ou pós-modernos, Freire também identifica tal fatalismo, que reforça a inexorabilidade do futuro, bloqueando, portanto, a emergência de inéditos viáveis (Freire, 2013).

Freire defende uma concepção de história, em que são plasmadas possibilidades para o futuro, permitindo que a consciência crítica supere a paralisia do sujeito frente ao medo do difícil ou do impossível, levando-o enfrentar as situações. Para tanto, é preciso identificar as razões que provocam tal medo, comparar com as possibilidades de que se dispõe para enfrentar com probabilidade de êxito e, caso seja adiado o enfrentamento do obstáculo, analisar o que é possível de ser feito para se tornar mais capaz na tarefa no futuro (Freire, 2016e). Portanto, trata-se de transformar as dificuldades em possibilidades, requerendo sujeitos nem só pacientes nem só impacientes, mas sujeitos pacientemente impacientes (Freire, 2013).

Contra a reprodução e a permanência do status quo, a prática educativa esperançosa atua no plano da mudança (Freire, 2014c). E não se restringindo à denúncia do presente, mas atuando no anúncio de um futuro diferente, os indivíduos também assumem os riscos para essas mudanças e para o protagonismo nas rupturas necessárias (Freire, 2016c).

A esperança, o sonho e a utopia são tratados como sinônimos na produção freireana e de seus comentadores e partem do princípio de que conhecer é a possibilidade de projetar, lançar-se adiante, buscar. Essa busca insere-se na perspectiva ontológica do homem como um ser inacabado, inconcluso, sendo a realização de sua história movida pela esperança.

Vale destacar que o sentido de utopia sofre inflexões ao longo da história, em que a conotação fantasiosa e irreal do conceito abre espaço, com Karl 
Mannheim (1976), no século XX, para uma abordagem menos absoluta que no marxismo clássico. Segundo esse autor, não haveria uma relação excludente entre utopia e realidade: a utopia assumiria um estatuto relativo, na medida em que a incongruência diria respeito à realidade imediata, mas não em relação ao futuro. Desse modo, a abordagem de Freire alinha-se com a perspectiva de que "a noção de utopia deixa o absolutamente inexequível para ingressar no futuramente viável" (Fraga, 2016, p. 5).

Ana Freire (2000) destaca a importância do sonho para os inéditos viáveis em Utopia e democracia: os inéditos-viáveis na educação cidadã e reitera a perspectiva dialética das mudanças, tendo como mote mudar a si, mudando o mundo e sendo por ele mudado.

Segundo a autora, dada a característica da inconclusão humana, a utopia humana não tem um fim, um termo definitivo de chegada, uma vez que aquilo que é alcançado já é transitório no caminho ético para a concretização da vocação ontológica dos seres humanos em seres mais. Neste sentido, ao ser atingido um inédito viável pelo qual se sonha e se luta, brotam-se outros tantos quantos caibam nos sentimentos e nas razões ditadas pelas necessidades humanas.

\section{Exemplos de inéditos viáveis: tentativas de tradução}

Paulo Freire, como dito, não se preocupou em cunhar um conceito para o inédito viável. Ao empreender-se em uma busca por exemplos trazidos por ele próprio e por seus comentadores que dessem pistas a respeito do termo, emergem uma variedade de cenas, cenários e indivíduos pouco elucidativos para se apreender 'o que é' ou 'o que seria' o inédito viável.

Um primeiro exemplo diz respeito à narração de uma situação envolvendo imigrantes espanhóis na Suíça, cuja situação-limite demandaria a construção de um projeto de contraescola - um inédito viável, diante da situação política e social dessa minoria naquele país, à época.

Os espanhóis viviam sob permanente tensão diante das experiências de trabalho. Muitos eram submetidos a restrições, como a de não poder estar junto aos seus familiares e incertezas sobre a renovação anual de presença legal no país. Ademais, o clima cultural, político e ideológico da Suíça era desfavorável a manifestações políticas de caráter público:

(...) eles [os imigrantes], mergulhados no 'cansaço existencial' e na 'anestesia histórica', girando em torno de seus problemas e de suas preocupações pessoais, não podiam divisar o 'inédito viável' mais além da 'situação-limite' em que se achavam imersos. Daí, também, a dificuldade de movê-los da 'anestesia histórica', geradora de uma certa apatia, de um certo imobilismo, à preocupação e ao debate de natureza política (Freire, 2014b, p. 190). 
A experiência de contraescola, que teve congruências com a Pedagogia do Oprimido, buscou problematizar a escola suíça que os filhos de imigrantes frequentavam oficialmente. Tomava, portanto, a própria experiência na escola 'oficial' como objeto de análise crítica, para que as crianças repensassem o que haviam aprendido ou estavam aprendendo, seja no currículo explícito, seja no oculto:

Os resultados positivos que alcançaram levaram os pais das crianças da escola problematizante, disseram-me eles em nosso encontro, a procurá-los, pedindolhes que fizessem para eles algo parecido. Uma outra escola em que pudessem discutir, juntos, sua presença na Suíça, a situação política da Espanha etc. Foi através da ideia posta em prática de uma escola que problematizasse a escola de seus filhos que chegaram a cursos ou a seminários ou a encontros de formação política para eles, pais (Freire, 2014b, p. 195).

Tal processo, portanto, conseguiu fazer com que fosse superada a apatia pela preocupação de natureza política dos trabalhadores imigrantes, levandoos à busca de formação para a participação política.

Ana Freire (2000) cita duas experiências de construção de inéditos viáveis em escolas; uma em Porto Alegre e outra em São Paulo, que visaram responder aos desafios administrativos, políticos e pedagógicos de reinvenção da escola pública no contexto de gestões municipais progressistas. Notadamente a respeito da experiência em São Paulo, Paulo Freire (1991, p. 34-35) menciona que:

Precisamos demonstrar que respeitamos as crianças, suas professoras, sua escola, seus país, sua comunidade; que respeitamos a coisa pública, tratando-a com decência. ( ...) Neste sentido é que reparar rapidamente as escolas é já mudar um pouco sua cara, não só do ponto de vista material, mas, sobretudo, de sua 'alma'. Precisamos deixar claro que acreditamos em quem e respeitamos quem se acha nas bases. (...) Mudar a cara da escola implicava em ouvir meninos e meninas, sociedade de bairro, pais, mães, diretoras de escola, delegados de ensino, professoras, supervisoras, comunidade científica, zeladores, merendeiras etc. Não se muda a cara da escola por um ato de vontade do Secretário.

Há também referências que trazem exemplos que não se coadunam com os contextos necessários para a emersão do inédito viável. Um deles é trazido por Vannucchi (2003), durante uma conferência realizada predominantemente para o público feminino, quando associa o inédito viável à possibilidade de se encontrar um relacionamento conjugal mais adequado:

Isso aqui [o inédito viável] é muito sábio, gente! Se vocês levarem desta noite, deste curso, deste projeto "Vivendo e Aprendendo", a certeza que isto é válido, 
muita coisa muda na própria vida! "Ah, eu queria ter o melhor rapaz do mundo, para casar com ele". Assim você vai se sair mal. Você também não vai dizer: "Ah! Eu caso com qualquer 'trequinho' que encontrar por aí". Assim também não. Procure o inédito viável. Procure o rapaz possível. Às vezes, o super-rico, o superbonito, o superdotado, o super-super, não é o melhor! Pode ser o pior (Vannucchi, 2003, p. 25).

Apesar do exemplo trazer a característica do possível realizável presente no inédito viável, ele carece de quaisquer outras bases que justifiquem uma correspondência entre ambos. A despeito de poder se tratar de uma mera brincadeira, esse tipo de exemplo pode reforçar um tom de resignação, absolutamente incompatível com a proposta freireana.

Por fim, Ana Freire (2000) menciona a teoria do conhecimento de Paulo Freire como um inédito viável, na medida em que contrapõe a educação tradicional - elitista, autoritária, deficiente e retrógrada - à educação libertadora e dialógica como utopia a ser atingida. Afirma também que a obra dele está absolutamente impregnada de inéditos viáveis, chegando a afirmar que o próprio Freire poderia ser personificado como um ser 'ineditamente viável'.

Pensar a produção da teoria de conhecimento de Paulo Freire como um inédito viável parece ser possível diante dos contextos anteriormente analisados, pois a criação desta nova perspectiva apresenta coerência com seus pressupostos praxiológicos. No entanto, identificar Paulo Freire como um ser ineditamente viabilizado, não obstante a importância do seu legado, parece não corresponder à ideia de uma futuridade derivada de um sonho coletivo.

Apesar de os exemplos identificados nas obras analisadas nem sempre ofertarem pistas para a sua apreensão que auxiliem numa certa tradutibilidade dos sentidos e dos contextos evidenciados anteriormente em situações práticas, foram destacados os termos que pareceram mais prenhes de significados para a noção de inédito viável.

$\mathrm{O}$ trecho de uma das obras foi particularmente inspirador e serviu como ponto de partida para se deslindar sentidos para o inédito viável:

Expressão utilizada por Paulo Freire para designar o devir, o 'ainda-não', o futuro a se construir, a futuridade a ser criada, o projeto a realizar. Inédito viável é a possibilidade ainda inédita de ação que não pode ocorrer a não ser que superemos as situações-limites (...), transformando a realidade na qual ela está com a nossa práxis (Gadotti, 2007, p. 109).

Às ideias de futuridade e de projeto somaram-se as de esperança, utopia e sonho, referidas nas seções anteriores, propondo-se circunscrever os sentidos de inédito viável com base na concepção de projeto coletivo. 


\section{Sentidos do inédito viável: assunção como projeto coletivo}

Não se pretende - nem é desejável - uma apreensão objetiva e objetivante do termo inédito viável. Nesse sentido, exploram-se aqui as suas potencialidades, expressas com base nos sentidos capturados na obra freireana, sobretudo para as práticas de saúde, vistas como práticas também pedagógicas.

Ana Maria Araújo Freire (2014a), em nota no livro Pedagogia da Esperança, parece ter inaugurado uma reflexão mais elucidativa da ideia de inédito viável, situando-o como:

(...) algo que o sonho utópico sabe que existe, mas que só será conseguido pela práxis libertadora (...) é na realidade uma coisa inédita, ainda não claramente conhecida e vivida, mas sonhada, e quando se torna um 'percebido-destacado' pelos que pensam utopicamente, esses sabem, então, que o problema não é mais um sonho, que ele pode se tornar realidade (Freire, 2014a, p. 278-279).

Como palavra-ação, que abriga "a compreensão do tempo e do espaço, da denúncia e do anúncio" (Freire, 2000, p. 15), o inédito viável expressa os projetos e os atos das possibilidades humanas para as transformações voltadas a um futuro mais humano e mais ético, com a construção de uma sociedade mais justa, alegre e fraterna.

Na obra Paulo Freire ao vivo ${ }^{9}$, Santos (2003) também relaciona os inéditos viáveis à ideia de projeto, ao apontar que a consciência crítica permite ao homem perceber-se como construtor do mundo, repercutindo na criação de suas utopias com horizontes de possibilidades, donde também se inserem os projetos a serem realizados.

Identifica-se que a menção aos inéditos viáveis não se dá no plano de um único indivíduo, mas dos sujeitos. Estes, ao relacionarem-se entre si mediados com o mundo objetivo, puderam construir não só saberes, mas também condições e relações de saberes, de estar no mundo e de pretensão de mudar o futuro. Isto ocorre porque "além de serem sonhos coletivos, deverão estar sempre a serviço da coletividade" (Freire, 2017b, p. 226): "se algum de nós pensasse em mudar o mundo sozinho, simplesmente na sua relação solitária com o mundo já dado, saberia, em pouco tempo, que isto não é um sonho possível. É um devaneio esquizofrênico sem possibilidades. Não é um inéditoviável" (Freire, 2000, p. 17).

Na mesma linha, na obra Pedagogia dos sonhos possíveis, o prefácio de Ana Lúcia Souza de Freitas (2014) também dá destaque à dimensão coletiva embutida no inédito viável, que emerge do sonho possível:

o ato de sonhar coletivamente, na dialeticidade da denúncia e do anúncio e na assunção do compromisso com a construção dessa superação, carrega em si um im- 
portante potencial (trans) formador que produz e é produzido pelo inédito viável, visto que o impossível se faz transitório na medida em que assumimos coletivamente a autoria dos sonhos possíveis (Freitas, 2014, p. 42).

O inédito viável representa uma alternativa que não se situa no campo das certezas, mas sim no das possibilidades. Trata-se de uma alternativa construída coletivamente, com base na vivência crítica do sonho almejado, e, portanto, não ocorre ao acaso e nem se constrói individualmente. A distância entre o sonhado coletivamente e o realizado cotidianamente pelos sujeitos é um espaço a ser ocupado pelos atos criadores, visto que "assumir coletivamente esse espaço de criação abre possibilidades para que se consolidem propostas transformadoras e ineditamente-viáveis" (Freitas, 2014, p. 43).

Não obstante a aparente intangibilidade da ideia de projeto, situada no campo das possibilidades, o inédito viável diz respeito à concretude dessas possibilidades transformadoras, conforme capturado em fragmentos de publicações que abordaram o tema:

(...) é a materialização historicamente possível do sonho almejado. É uma proposta prática de superação, pelo menos em parte, dos aspectos opressores percebidos no processo de conhecimento que toma como ponto de partida a análise crítica da realidade. O risco de assumir a luta pelo inédito-viável é, pois, uma decorrência da natureza utópica, própria da consciência crítica, e encerra em si uma perspectiva metodológica, visto que faz do ato de sonhar coletivamente um movimento transformador (Freitas, 2005, p. 6).

Representa a responsabilidade política em anunciar uma possibilidade concreta como alternativa ao que denuncia. É expressão concreta da assunção do risco de criar novas possibilidades (...) (Freitas, 2004, p. 99).

Paulo Freire mostra a história e a existência humana como feixe de possibilidades e virtualidades que podem, pela prática histórica, ser levadas à concretização. Daqui nasce a esperança histórica, aquilo que ele chama de 'inédito viável', vale dizer, aquilo que ainda não foi ensaiado e é inédito, mas que pode, pela ação articulada dos sujeitos históricos, vir a ser ridente realidade (Boff, 2014, p. 113).

O projeto coletivo não estaria vinculado somente à vontade, mas constituirse-ia numa atitude de formação (Freitas, 2005). É certo que, por tudo o que edifica a pedagogia freireana, o sentido de formação, nesse domínio, rejeita qualquer tipo de associação com adestramento, treino de habilidades ou repasse de conteúdos. Assim, Ana Freire (2016a), em Pedagogia da solidariedade toma a pedagogia crítica, ética, política e libertária como propulsora do saber 
que precisa ser desvelado, apreendido, aprendido, vivido e comunicado, mas nunca estendido ou imposto.

Nesse ponto, cabe retomar a pertinência do constructo do inédito viável para o campo e práticas de saúde. Se a conclamada crise na saúde tem conformado o imaginário social como algo para além da nossa capacidade de superá-la, e ratificando a importância de uma formação para construção de inéditos viáveis, traremos alguns pontos para reflexão acerca de uma 'pedagogia dos inéditos viáveis'.

\section{À guisa de conclusão: por uma pedagogia dos inéditos viáveis na saúde}

A ideia de uma pedagogia dos inéditos viáveis não é nova e já foi explorada por autoras como Ana Maria Freire e Ana Lucia Freitas.

Freitas (2005), ao desenhar uma perspectiva metodológica do inédito viável, resgatando Ana Freire e o próprio Paulo Freire, coloca em relevo as dimensões política, ética, epistemológica e estética como planos que, articuladamente, fazem parte da construção do inédito viável.

A vontade está localizada no 'plano do querer' e corresponde à dimensão política da proposição metodológica. No 'plano do refletir', ela situa-se na dimensão epistemológica, que, movida pela curiosidade, possibilita ampliar a compreensão das razões de ser das situações-limite, assim como dos motivos que tornam imprescindível a luta pelo sonho. O 'plano do agir' incorpora a dimensão estética, o qual inclui os elementos que se referem à subjetividade, tais como a intuição, a emoção, o prazer, a amorosidade e a alegria. A articulação destes três planos possibilitaria a percepção dos temas contidos nas situações-limite, que, quando levados à reflexão crítica, permitiriam vislumbrar o ainda não experimentado para além dessas situações e em contradições com elas (Freitas, 2005).

A abordagem metodológica proposta dá pistas sobre como se configuraria uma formação para o inédito viável, valendo explorar o próprio sentido de formação. Não sendo um plano técnico, com regras e preceitos definidos $a$ priori, a formação enseja desafios práticos à sua concretização.

Nas trilhas de Ayres (2004), há que se registrar a distinção filosófica entre os saberes de natureza científica (epistéme) e técnica (techné) e a phrónesis sabedoria que, na filosofia aristotélica, refere-se a uma racionalidade voltada à práxis. A capacidade de antecipação e escolha prévia de escolher e negociar livremente no contexto da pólis, entre diferentes possibilidades de modos de vida, remete à ética, à política e à estética.

Do binômio 'denúncia-anúncio', dois aspectos mostraram-se particularmente importantes. Primeiro, o fato de que o inédito viável, além de pressupor o sonho e a utopia, também prevê a ação, pois encerra em si uma perspectiva metodológica. O segundo aspecto indica que esse sonho é um sonho coletivo. 
É da articulação entre essas duas perspectivas que o inédito viável pode ser tomado como um projeto coletivo a ser iniciado, no momento em que algo do mundo estabelecido, reproduzido e, por vezes, naturalizado, é tomado como estranho e é colocado em evidência. Este estranhamento tem o sentido de melhor compreender o que 'há de errado com ele' e, ao reconhecê-lo como injusto, como uma situação-limite, buscam-se alternativas para fazer face a esse algo ou aos contextos nos quais são produzidos. E, não menos complexo, é empreender todo esse processo coletivamente.

A esperança, a curiosidade e a motivação para a ação, bem como a leitura crítica da realidade, não são ensinadas, no sentido clássico de um conjunto de conteúdos transmitidos do educador para um educando. O investimento em formação na saúde reclama muito mais que isso: requer o compromisso coletivo com as possibilidades de mudança e as mudanças, além da abertura a projetos coletivos.

Em um campo tão impregnado pela dimensão técnica do trabalho, a formação na saúde impõe desafios para além de conteúdos e de bancos escolares. A universidade pública pode ser um espaço privilegiado de formação, mas ela tem simplesmente reproduzido o status quo, uma vez que, por exemplo, suspende estágios em unidades de saúde em locais violentos, somente com a justificativa da segurança dos estudantes, sem problematizar a própria violência.

Reconhece-se, por exemplo, o potencial da Política Nacional de Educação Permanente, como uma proposta ético-política-pedagógica que pretende integrar ensino, serviço e comunidade, mas indaga-se o quanto ela, de fato, expressa um projeto coletivo.

Como engendrar a construção de inéditos viáveis, senão a partir de uma perspectiva formativa e não meramente adestradora ou modeladora de comportamentos definidos a priori, e que tão só reproduzem interesses e expectativas de determinados setores da sociedade? Como transcender à mera inovação tecnológica em favor da construção de inéditos viáveis? Como tornar ineditamente viáveis as ideias de 'projeto' e de 'coletivo'?

Se a crise na saúde é reduzida a uma questão técnica, de alocação de recursos, mão de obra e acesso a equipamentos, reproduz-se a lógica desenvolvimentista de volúpia por uma inovação tecnológica que nem sempre tem a ver com as reais necessidades de saúde da população. Quando se destaca e tematiza as condições de emergência e persistência dessa crise, talvez a inovação, por si só, não possa contribuir nessa compreensão, e muito menos na transformação dessas condições. Carecemos de inovação no seio dos inéditos viáveis. 


\section{Colaboradores}

Os pesquisadores participaram de todas as etapas da pesquisa e redação do manuscrito.

\section{Financiamento}

Não houve financiamento.

\section{PAULO FREIRE Y LO INÉDITO VIABLE: ESPERANZA, UTOPÍA Y TRANSFORMACIÓN EN LA SALUD}

Resumen Este es un ensayo sobre lo "inédito viable" de Paulo Freire, con el objetivo de explorar su potencial en la salud colectiva. Se analizaron un total de 38 obras del autor, nueve de las cuales se referían a lo inédito viable, permitiendo el reconocimiento de significados subyacentes de la construcción. Se exploraron tres ejes para la comprensión: condiciones y contextos de emergencia de los inéditos viables; ejemplos; y significados de inéditos viables. La aparición de los inéditos viables es el resultado de un complejo proceso pedagógico, que va desde la extrañeza de la realidad hasta la percepción crítica de los sujetos involucrados, lo que permite la construcción de inéditos viables, como paso previo a la acción. Aunque algunas de las obras analizadas citan ejemplos de inéditos viables, éstos no fueron explicativos a la hora de captar posibles significados de lo inédito viable. A partir de las ideas de la obra freireana de praxis, proyecto, futuro, sueño, utopía y esperanza, la comprensión de lo viable inédito se ancló en el sentido de proyecto colectivo. Se propone una pedagogía aplicada a la salud colectiva que incorpora lo "inédito viable" como posibilidad de trascender la formación técnica, basada exclusivamente en contenidos informativos, invirtiendo también en las capacidades de indignación y denuncia y en la construcción de proyectos colectivos. Palabras clave inédito viable; educación popular; transformación social; esperanza; utopía. 


\section{Notas}

${ }^{1}$ A despeito das diversas designações possíveis para nomear a compreensão de educação proposta por Freire (tais como: pedagogia libertadora, pedagogia crítico-problematizadora, pedagogia do oprimido, entre outras), optou-se, aqui, por adotar o termo 'educação popular'.

2 Trata-se da esposa de Paulo Freire que foi casada com ele desde 1988. Como ela adotou o seu sobrenome e utilizamos algumas de suas produções (ela organizou algumas das obras de Freire, escreveu as notas explicativas de outros, assim como também produziu textos aportando ao trabalho dele), toda vez que a citamos, utilizamos o seu primeiro nome para indicar que se trata de uma produção dela.

${ }^{3}$ Este trabalho faz parte do projeto de Tese de Doutorado desenvolvida no Instituto de Estudos em Saúde Coletiva da Universidade Federal do Rio de Janeiro, do primeiro autor sob a orientação das demais autoras. O autor principal é bolsista da Coordenadoria de Aperfeiçoamento de Pessoal de Nível Superior (CAPES). Como este trabalho não foi desenvolvido com seres humanos, não houve sua submissão para apreciação em Comitê de Ética em Pesquisa. Os autores declaram não haver conflitos de interesses.

4 “Educação e atualidade brasileira" (1959), "A propósito de uma administração" (1961), "Educação como prática da liberdade" (1967), "Pedagogia do oprimido" (1968), "Extensão ou comunicação?" (1968), “Ação cultural para a liberdade e outros escritos" (1975), "Educação e mudança”" (1976), “Cartas à Guiné-Bissau - registros de uma experiência em processo" (1977), "Conscientização" (1979), "Partir da infância: diálogos sobre educação" (1981), "A importância do ato de ler: em três artigos que se completam" (1982), "Paulo Freire ao vivo" (1983), "Educar com a mídia: novos diálogos sobre educação" (1984), "Por uma pedagogia da pergunta" (1985), "Pedagogia: diálogo e conflito" (1985), "Essa escola chamada vida: depoimentos ao repórter Ricardo Kotscho" (1985), "Aprendendo com a própria história" (1987), "Medo e ousadia: o cotidiano do professor" (1987), "Que fazer: teoria e prática em educação popular" (1988), "Disciplina na escola: autoridade versus autoritarismo" (1989), "Educadores de rua: uma abordagem crítica" (1989), "Alfabetização: leitura do mundo, leitura da palavra" (1990), "A educação na cidade" (1991), "Pedagogia da esperança: um reencontro com a pedagogia do oprimido" (1992), "Política e educação: ensaios" (1993), "Professora, sim; tia, não: cartas a quem ousa ensinar" (1993), "Cartas a Cristina: reflexões sobre minha vida e minha práxis" (1994), "À sombra desta mangueira" (1995), "Pedagogia da autonomia: saberes necessários à prática educativa" (1996), "Aprendendo com a própria história II" (2000), "Pedagogia da indignação: cartas pedagógicas e outros escritos" (2000), "Pedagogia dos sonhos possíveis" (2001), "O caminho se faz caminhando: conversas sobre educação e mudança social" (2002), "A África ensinando a gente: Angola, Guiné-Bissau, São Tomé e Príncipe" (2003), "Pedagogia do compromisso: América Latina e educação popular" (2003), "Pedagogia da tolerância" (2005), “Sobre educação: lições de casa" (2008) e "Pedagogia da solidariedade" (2009).

${ }^{5}$ Para além do termo 'inédito viável', também foram utilizadas algumas variações adotadas pelo autor em suas obras: 'inédito-viável', 'inéditos viáveis', 'inéditos-viáveis', 'ineditamente viável', 'ineditamente-viável' e 'ineditamente viáveis'.

${ }^{6}$ O Instituto Superior de Estudos Brasileiros (ISEB) foi um órgão vinculado ao Ministério da Educação brasileiro no período de 1955 a 1964. Era constituído por um grupo de intelectuais radicados no Rio de Janeiro com vistas ao estudo, ensino e divulgação dos 
saberes das ciências sociais para a análise e compreensão crítica da realidade brasileira. A partir da ideologia que se configurou o Projeto Nacional Desenvolvimentista na época, o ISEB buscava uma ação de cunho político expresso na intervenção e no direcionamento de uma nova mentalidade da sociedade voltada à superação do subdesenvolvimento do país (Oliveira, 2006).

${ }^{7}$ Este termo também pode ser encontrado em sua obra como 'decodificação'. Apesar de ambos serem aceitos pela língua portuguesa, optou-se, neste trabalho, por utilizar 'descodificação' por ser a fórmula geral preferencial (Houaiss; Villar, 2001).

${ }^{8}$ Deriva da sua participação no "VII Seminário Internacional de Reestruturação Curricular: utopia e democracia - Os inéditos viáveis na educação cidadã" promovido pela Secretaria Municipal de Educação de Porto Alegre em 2000.

9 Trata-se da reprodução de três seminários de Freire no "Projeto Vivendo e Aprendendo" realizado em 1980, na Faculdade de Filosofia, Ciência e Letras de Sorocaba e de uma conferência apresentada no mesmo local no ano seguinte. Dentre seus objetivos, o encontro buscava "descobrir propostas alternativas de ação que estimulem a reflexão sobre como mudar nossa prática, para que a educação desempenhe um papel conscientizador e transformador da realidade" (Freire, 2003, p. 5). O evento contou com duas palestras preliminares de professores desta faculdade: Wlademir dos Santos e Aldo Vannucchi. 


\section{Referências}

AYRES, José R. C. M. Norma e formação: horizontes filosóficos para as práticas de avaliação no contexto da promoção da saúde. Ciência \& Saúde Coletiva, v. 9, n. 3, p. 583-592, 2004.

BARDIN, Laurence. Análise de conteúdo. Lisboa: Edições 70, 2016.

BOFF, Leonardo. Prefácio. In: FREIRE, Paulo (Org.). Pedagogia da esperança: um reencontro com a pedagogia do oprimido. 21. ed. São Paulo: Paz e Terra, 2014. p. 9-12.

BRASIL, Ministério da Saúde. Secretaria de Gestão Estratégica e Participativa. Comitê Nacional de Educação Popular em Saúde. Política Nacional de Educação Popular em Saúde. Brasília: MS, 2012.

FRAGA, Paulo D. Utopia: roteiro de um conceito. Revista Espaço Acadêmico, n. 186, p. 1-7, 2016.

FREIRE, Ana M. A. Algumas palavras ou considerações em torno da Conferência de Paulo Freire. In: FREIRE, Paulo; FREIRE, Ana Maria Araújo; OLIVEIRA, Walter Ferreira De (Orgs.). Pedagogia da solidariedade. 2. ed. São Paulo: Paz e Terra, 2016a. p. 49-69.

FREIRE, Ana M. A. Bibliografia de Paulo Freire. In: STRECK, Danilo R.; REDIN, Euclides; ZITKOSKI, Jaime J. (Orgs.). Dicionário Paulo Freire. 3. ed. Belo Horizonte: Autêntica, 2017a. p. 433-438.

FREIRE, Ana Maria Araújo. Inédito viável. In: STRECK, Danilo R.; REDIN, Euclides; ZITKOSKI, Jaime J. (Orgs.). Dicionário Paulo Freire. 3. ed. Belo Horizonte: Autêntica, 2017b. p. 223-226.

FREIRE, Ana M. A. Notas explicativas. In: FREIRE, Paulo (Org.). Pedagogia da esperança: um reencontro com a pedagogia do oprimido. 21. ed. São Paulo: Paz e Terra, 2014a. p. 273-333.

FREIRE, Ana M. A. Utopia e democracia: os inéditos-viáveis na educação cidadã. In: AZEVEDO, José Clóvis de et al. (Orgs.).
Utopia e democracia na educação cidadã. Porto Alegre: Editora da Universidade (UFRGS), 2000. p. 13-21.

FREIRE, Paulo. A Educação na cidade. São Paulo: Cortez, 1991.

FREIRE, Paulo. À sombra desta mangueira. 11. ed. Rio de Janeiro: Paz e Terra, 2013.

FREIRE, Paulo. Ação cultural para a liberdade e outros escritos. 15. ed. Rio de Janeiro: Paz e Terra, 2015.

FREIRE, Paulo. Conscientização. Tradução de Tiago José Risi Leme. São Paulo: Cortez, 2016b.

FREIRE, Paulo. Educação como prática da liberdade. 42. ed. Rio de Janeiro; São Paulo: Paz e Terra, 2018.

FREIRE, Paulo. Paulo Freire ao vivo. 2. ed. Rio de Janeiro: Paz e Terra, 2003.

FREIRE, Paulo. Pedagogia da Esperança. In: FREIRE, Paulo (Org.). Pedagogia da esperança: um reencontro com a pedagogia do oprimido. 21. ed. São Paulo: Paz e Terra, 2014b. p. 21-272.

FREIRE, Paulo. Primeiras palavras. FREIRE, Paulo. Pedagogia da esperança: um reencontro com a pedagogia do oprimido. 21. ed. São Paulo: Paz e Terra, 2014c. p. 13-19.

FREIRE, Paulo. Pedagogia da indignação: cartas pedagógicas e outros escritos. 3. ed. São Paulo: Paz e Terra, 2016c.

FREIRE, Paulo. Pedagogia do oprimido. 62. ed. Rio de Janeiro: Paz e Terra, 2016d.

FREIRE, Paulo. Pedagogia dos sonhos possiveis. São Paulo: Paz e Terra, 2014d.

FREIRE, Paulo. Professora sim, tia não: cartas a quem ousa ensinar. 26. ed. São Paulo: Paz e Terra, 2016e.

FREITAS, Ana L. S. Pedagogia da conscientização: um legado de Paulo Freire à for- 
mação de professores. 3. ed. Porto Alegre: EDIPUCRS, 2004.

FREITAS, Ana L. S. Pedagogia do inédito-viável: contribuições de Paulo Freire para fortalecer o potencial emancipatório das relações ensinar-aprender-pesquisar. In: COLÓQUIO INTERNACIONAL PAULO FREIRE: DESAFIOS À SOCIEDADE MULTICULTURAL, 5., 2005, Recife. Anais eletrônicos... Recife: Centro Paulo Freire de Estudos e Pesquisas, 2005. Disponível em: < https://edisciplinas.usp.br/ pluginfile.php/1821773/mod_folder/content/0/ Leitura $\% 20$ complementar/Pedagogia $\% 20$ do $\% 20$ in $\%$ C3\% A9dito $\% 20$ vi $\%$ C3\%Alvel $\% 20-\% 20$ Ana $\% 20$ Freitas.PDF? forcedownload $=1>$. Acesso em: 3 jun. 2018.

FREITAS, Ana L. S. Prefácio - Pedagogia dos sonhos possíveis: a arte de tornar possível o impossível. In: FREIRE, Paulo (Org.). Pedagogia dos sonhos possíveis. São Paulo: Paz e Terra, 2014. p. 39-45.

GADOTTI, Moacir (Org.). Paulo Freire: uma biobibliografia. São Paulo: Cortez; Instituto Paulo Freire, 1996.

GADOTTI, Moacir. A escola e o professor: Paulo Freire e a paixão de ensinar. São Paulo: Publisher Brasil, 2007.

GOLDMANN, Lucien. The human sciences and philosophy. Londres: Jonathan Cape, 1969.

HOUAISS, Antônio; VILLAR, Mauro S. Minidicionário Houaiss da Língua Portuguesa. Rio de Janeiro: Objetiva, 2001.

MANNHEIM, Karl. Ideologia e utopia. Rio de Janeiro: Zahar, 1976.

MANTOVANI, Rafael. O que foi a polícia médica? História, Ciências, Saúde-Manguinhos, Rio de Janeiro, v. 25, n. 2, p. 409-427, 2018.

NICOLAÏ, André. Comportement économique et structures sociales. Paris: Presses Universitaires de France, 1960.
OLIVEIRA, Maria T. C. O Instituto Superior de Estudos Brasileiros - ISEB: uma singular experiência educativa concebida no âmbito do projeto de desenvolvimento nacional. In: CONGRESSO BRASILEIRO DE HISTÓRIA DA EDUCAÇÃO, 4., 2006, Goiânia. Anais eletrônicos... Goiânia: SBHE, 2006. Disponível em: $<$ http://www.sbhe.org.br/novo/congressos/ cbhe4/individuais-coautorais/eixo06/Maria \%20 Teresa $\% 20$ Cavalcanti $\% 20$ de $\% 20$ Oliveira $\% 20$ -\%20Texto.pdf>. Acesso em: 3 jun. 2018.

SANTOS, Wlademir. Paulo Freire ao vivo. 2. Ed. São Paulo: Loyola, 2003.

SIMÕES, Sérgio L. Pedagogia do neologismo: a linguagem de Paulo Freire e a educação libertadora. 200fl. Tese (Doutorado em Educação) - Programa de Pós-Graduação em Educação da Universidade Nove de Julho, São Paulo, 2013.

STRECK, Danilo R.; REDIN, Euclides; ZITKOSKI, Jaime J. Dicionário Paulo Freire. 3. ed. Belo Horizonte: Autêntica, 2017.

VANNUCCHI, Aldo. O embasamento metodológico. In: FREIRE, Paulo (Org.). Paulo Freire ao vivo. 2. ed. São Paulo: Loyola, 2003. p. 20-43.

VASCONCELOS, Eymard M. Redefinindo as práticas de saúde a partir de experiências de educação popular nos serviços de saúde. Interface: Comunicação, Saúde e Educação, Botucatu, v. 5, n. 8, p. 121-126, 2001.

VIEIRA PINTO, Álvaro. Consciência e realidade nacional: a consciência crítica. v. 2. Rio de Janeiro: ISEB, 1960.

ZITKOSKI, Jaime J. Dialética. In: STRECK, Danilo R.; REDIN, Euclides; ZITKOSKI, Jaime J. (Orgs.). Dicionário Paulo Freire. 3. ed. Belo Horizonte: Autêntica, 2017. p. 115-117. 